\title{
Relationship between threatened miscarriage and gestational diabetes mellitus
}

\author{
Hee Joong Lee ${ }^{1}$, Errol Norwitz ${ }^{2}$ and Banghyun Lee ${ }^{3^{*}}$ (D)
}

\begin{abstract}
Background: Both threatened miscarriage and gestational diabetes mellitus (GDM) are common complications of pregnancy. However, only one pilot study has reported that these complications are not related. We aimed to investigate whether threatened miscarriage is one of the risk factors of GDM.

Methods: An unmatched case-control study of 1567 pregnant Korean women who underwent a two-step approach to diagnose GDM was retrospectively conducted. The eligible women were classified into normal $(n=840)$, borderline GDM $(n=480)$, and GDM $(n=247)$ groups. We analyzed the associations with threatened miscarriage in all groups with adjustment for confounding factors.

Results: The proportion of women who experienced threatened miscarriage was significantly lower in the GDM group than in the normal group (adjusted odds ratio (OR), 0.38; 95\% confidence interval (CI), 0.18-0.78). It was significantly lower in the maternal hyperglycemia group (borderline GDM and GDM groups) than in the normal group (adjusted $\mathrm{OR}, 0.66 ; 95 \% \mathrm{Cl}, 0.47-0.91)$. The proportion of women who experienced threatened miscarriage was also significantly lower in the GDM group than in the normal (adjusted OR, 0.35; 95\% Cl, 0.17-0.70) and borderline GDM groups (adjusted $\mathrm{OR}, 0.46 ; 95 \% \mathrm{Cl}, 0.22-0.94$ ). Moreover, the proportion of women who experienced threatened miscarriage significantly decreased according to the severity of glucose intolerance (adjusted OR, 0.94; 95\% Cl, 0.76-1.16).

Conclusion: This study demonstrates that threatened miscarriage is associated with decreased risk of GDM and the severity of glucose intolerance in Korean women. Additional studies are warranted to understand the pathophysiologic mechanisms that might exist between these frequent complications of pregnancy.
\end{abstract}

Keywords: Gestational diabetes mellitus, Threatened miscarriage, Borderline GDM, Maternal hyperglycemia

\section{Background}

Threatened miscarriage, which is defined as any vaginal bleeding that occurs during the first half of a pregnancy, occurs in an estimated $14-20 \%$ of all pregnant women (14.8\% in Korean women) [1,2]. Approximately $50 \%$ of women who experienced threatened miscarriage eventually suffer miscarriages [3, 4]. Bleeding that originates from the uteroplacental vessels between the chorionic membrane and the uterine wall is often considered to be the most common cause of vaginal bleeding in threatened miscarriage [3]. Depending on the severity of bleeding,

\footnotetext{
* Correspondence: banghyun.lee@gmail.com

${ }^{3}$ Department of Obstetrics and Gynecology, Hallym University Kangdong Sacred Heart Hospital, 150, Seongan-ro, Gangdong-gu, Seoul, Republic of Korea

Full list of author information is available at the end of the article
}

miscarriage can occur [3]. Many studies have reported that threatened miscarriage is associated with an increased risk of adverse obstetric outcomes, such as antepartum hemorrhage, preterm delivery, cesarean delivery, preterm premature rupture of membrane (PPROM), pregnancy-induced hypertension, preeclampsia, placenta previa, and placenta abruption, and adverse perinatal outcomes, such as perinatal death, small-for-gestational-age (SGA) infants and low birth weight $[1,3,5,6]$.

Maternal hyperglycemia occurs when insulin secretion from pancreatic $\beta$ cells is inadequate for the increased insulin requirements during pregnancy [7]. Gestational diabetes mellitus (GDM) is defined as any severity of maternal hyperglycemia with onset or first recognition during pregnancy $[8,9]$. However, a fasting plasma

(c) The Author(s). 2018 Open Access This article is distributed under the terms of the Creative Commons Attribution 4.0 International License (http://creativecommons.org/licenses/by/4.0/), which permits unrestricted use, distribution, and 
glucose level $>7.0 \mathrm{mmol} / \mathrm{L}$ or a casual plasma glucose $>11.1 \mathrm{mmol} / \mathrm{L}$ meets the threshold for type 2 diabetes diagnosis [8]. The prevalence of GDM ranges between 1 and $14 \%$ depending on the risk level of the affected population (5.7-9.5\% in Korean women) [9-12]. Borderline GDM is usually considered to be maternal hyperglycemia that does not meet the diagnostic criteria for GDM and type 2 diabetes [10]. Although no clear consensus has been reached, 1 - $\mathrm{h}$ venous plasma glucose $\geq 7.8$ or $7.2 \mathrm{mmol} / \mathrm{L}$ on a positive $50 \mathrm{~g}$ oral glucose challenge test (OGCT) is considered a minimum glucose level for borderline GDM diagnosis [13, 14]. Several studies have reported that borderline GDM occurs in approximately 7-9\% of all pregnant women [10].

Progesterone is essential for establishment and maintenance of pregnancy $[15,16]$. Low progesterone levels are associated with an increased risk of first trimester miscarriage [17]. Recently, some studies reported that progesterone therapy during early pregnancy in women with threatened miscarriage may reduce pregnancy loss and the risk of adverse obstetric and perinatal outcomes [17-20]. Insulin resistance in pregnancy normally increases during the second and third trimesters [21]. Several studies in rats, mice, and adipocytes have reported that progesterone induces insulin resistance by multiple mechanisms during pregnancy [22-24]. The use of 17-alpha hydroxyprogesterone caproate for preterm delivery prevention is associated with an increased risk of developing GDM $[25,26]$. Therefore, we hypothesized that women with threatened miscarriage possess lower levels of progesterone throughout pregnancy than those without threatened miscarriage. As a result, women with threatened miscarriage may have less insulin resistance during the second and third trimesters of pregnancy than those without threatened miscarriage, followed by a lower risk for glucose intolerance.

Both threatened miscarriage and GDM are common complications of pregnancy. Whether threatened miscarriage is associated with GDM warrants evaluation. To our knowledge, only one small-scale pilot study performed in Europe has reported that no relationship exists between threatened miscarriage and GDM [27]. Therefore, in the present study, we aimed to investigate whether threatened miscarriage is a risk factor of GDM and to evaluate this relationship according to the severity of glucose intolerance.

\section{Methods}

This study was approved by the Institutional Review Board of The Catholic Medical Center at the Catholic University of Korea (No. XC14RIMI0013U) on February 1, 2014. Informed consent was waived. We reviewed the medical records of pregnant women who enrolled in the routine prenatal care program of Seoul or Uijeongbu St. Mary's Hospital at the Catholic University of Korea before 12 weeks of gestation and who gave birth in the same hospital from January 1, 2006 to October 31, 2013. Pregnant women who underwent a two-step approach to diagnose GDM were included [7]. The exclusion criteria were as follows: women who did not undergo a 100-g oral glucose tolerance test (OGTT) after a positive 50-g OGCT; women who had other causes of vaginal bleeding (e.g., post-coital bleeding, polyp, vaginitis) at the time of assessment; women with fetal anomalies, multifetal gestation, or overt diabetes mellitus; and non-Korean ethnicity. Because only 3 non-Korean women met the study criteria, they were excluded from this study.

The medical records of 1567 pregnant women who were eligible for the study were reviewed. A total of 247 pregnant women were diagnosed with GDM. Borderline GDM and normal groups included 480 and 840 pregnant women, respectively.

In Seoul and Uijeongbu St. Mary's Hospitals (the tertiary and secondary hospitals), the routine protocol to diagnose GDM was based on a two-step approach that consisted of a universal 50-g OGCT and a diagnostic 100-g OGTT [7]. A 50-g OGCT was performed at 24-28 weeks of gestation. Plasma glucose level $>7.8 \mathrm{mmol} / \mathrm{L}$ at 1-h post-glucose load without prior fasting was regarded as a positive GDM screening result, and a diagnostic 100-g OGTT was then recommended. In the diagnostic 100-g OGTT, the fasting plasma glucose levels were measured prior to glucose load ingestion, and three plasma glucose levels were measured at 1,2 , and $3 \mathrm{~h}$ following the glucose load ingestion. To diagnose GDM, we used the Carpenter and Coustan criteria, which included women with two or more plasma glucose measurements greater than the following thresholds: fasting glucose of $\geq 5.3 \mathrm{mmol} / \mathrm{L}, 1$-h glucose of $\geq 10.0 \mathrm{mmol} / \mathrm{L}, 2$ - $\mathrm{h}$ glucose of $\geq 8.6 \mathrm{mmol} / \mathrm{L}$, and 3 -h glucose of $\geq 7.8 \mathrm{mmol} / \mathrm{L}$ [28]. Borderline GDM in women was defined as a positive OGCT and a negative diagnostic OGTT (in which plasma glucose measurements greater than the thresholds were absent or only one value was greater than the threshold). The pregnant women with GDM were managed with diet control, exercise, careful glucose monitoring, and medication (insulin therapy or oral hypoglycemic agents). In this study, $14.6 \%(n=36)$ of the 247 women with GDM were managed with insulin (2 women were managed with oral hypoglycemic agents after insulin use for 2 months) and $85.4 \%(n=211)$ were managed with diet control. The pregnant women with borderline GDM were managed with the same routine prenatal care as the healthy pregnant women, except for one woman who was administered with insulin.

Gestational age was calculated from the last menstrual period (LMP) and was confirmed by the crown-rump length (CRL), which was measured using ultrasound during the first trimester. If the CRL dating differed by 
more than 7 days from the LMP dating, gestational age was changed according to the CRL dating [27, 29]. Threatened miscarriage was defined as women whose medical records documented vaginal bleeding before 20 weeks of gestation [1]. Data regarding the amount of bleeding and the number of bleeding episodes were extracted from the medical records of the patients. Threatened miscarriage was classified as "light" if the bleeding was written as scanty or small amounts in the medical record; otherwise, it was classified as "heavy" [5]. Intrauterine hematoma was defined as a crescent-shaped echolucent area between the chorionic membranes and the placenta and/or the myometrium on ultrasound [1]. All eligible women were classified as either women who experienced threatened abortion $(n=194)$ or women who did not experience threatened miscarriage $(n=1373)$. One woman with GDM and two women with borderline GDM received weekly intramuscular injections of progesterone (250 mg, 1 to 3 times).

Pre-pregnancy body mass index (BMI) was calculated using the baseline weight (self-reported pre-pregnancy weight or weight measured at the first visit during early

Table 1 Clinical characteristics of the normal and GDM groups

\begin{tabular}{|c|c|c|c|c|c|c|}
\hline & $\begin{array}{l}\text { Total } \\
(n=1087)\end{array}$ & $\begin{array}{l}\text { Normal } \\
(n=840)\end{array}$ & $\begin{array}{l}\text { GDM } \\
(n=247)\end{array}$ & $p^{b}$ & OR $(95 \% \mathrm{Cl})$ & $p^{c}$ \\
\hline Maternal age (years), mean $\pm S D$ & $34.1 \pm 3.9$ & $33.9 \pm 3.9$ & $34.7 \pm 4.0$ & 0.003 & $1.06(1.02-1.10)$ & 0.003 \\
\hline$<35, \mathrm{n}(\%)$ & $623(57.3)$ & $498(59.3)$ & $125(50.6)$ & 0.015 & ref & 0.016 \\
\hline$\geq 35, \mathrm{n}(\%)$ & $464(42.7)$ & $342(40.7)$ & $122(49.4)$ & & $1.42(1.07-1.89)$ & \\
\hline Parity, n (\%) & & & & 0.003 & & 0.003 \\
\hline Primipara & $613(56.4)$ & $494(58.8)$ & $119(48.2)$ & & ref & \\
\hline Multipara & $474(43.6)$ & $346(41.2)$ & $128(51.8)$ & & $1.54(1.16-2.04)$ & \\
\hline Intrauterine hematoma, n (\%) & $80(7.4)$ & $72(8.6)$ & $8(3.2)$ & 0.005 & $0.36(0.17-0.75)$ & 0.007 \\
\hline Gestational age at birth (weeks), mean \pm SD & $38.6 \pm 1.6$ & $38.8 \pm 1.4$ & $38.0 \pm 2.0$ & $<0.001$ & $0.74(0.68-0.82)$ & $<0.001$ \\
\hline Preterm delivery (before 37 weeks), n (\%) & $78(7.2)$ & $45(5.4)$ & $33(13.4)$ & $<0.001$ & $2.72(1.70-4.38)$ & $<0.001$ \\
\hline Delivery methods, n (\%) & & & & $<0.001$ & & \\
\hline Normal delivery & $718(66.1)$ & $588(70.0)$ & $130(52.6)$ & & ref & \\
\hline Operative delivery (vacuum) & $12(1.1)$ & $10(1.2)$ & $2(0.8)$ & & $0.91(0.20-4.18)$ & 0.90 \\
\hline Primary cesarean section & $170(15.6)$ & $121(14.4)$ & 49 (19.8) & & $1.83(1.25-2.69)$ & 0.002 \\
\hline Repeat cesarean section & $187(17.2)$ & $121(14.4)$ & $66(26.7)$ & & $2.47(1.73-3.52)$ & $<0.001$ \\
\hline PROM, n (\%) & $186(17.1)$ & $148(17.6)$ & $38(15.4)$ & 0.41 & $0.85(0.58-1.25)$ & 0.41 \\
\hline PPROM, n (\%) & $38(3.5)$ & $25(3.0)$ & $13(5.3)$ & 0.09 & $1.81(0.91-3.60)$ & 0.09 \\
\hline Preeclampsia, n (\%) & $19(1.8)$ & $8(1.0)$ & $11(4.5)$ & 0.001 & $4.85(1.93-12.19)$ & 0.001 \\
\hline Placenta previa, n (\%) & $27(2.5)$ & $17(2.0)$ & $10(4.0)$ & 0.07 & $2.04(0.92-4.52)$ & 0.08 \\
\hline Placenta abruption, n (\%) & $7(0.6)$ & $7(0.8)$ & $0(0.0)$ & 0.36 & $0.35(0.00-1.81)$ & 0.33 \\
\hline Still birth, n (\%) & $3(0.3)$ & $3(0.4)$ & $0(0.0)$ & $>0.999$ & $0.88(0.00-5.84)$ & 0.92 \\
\hline History of prior GDM, n (\%) & $53(4.9)$ & $1(0.1)$ & $52(21.1)$ & $<0.001$ & $58.4(37.73->999.99)$ & $<0.001$ \\
\hline $50 \mathrm{~g} \mathrm{OGCT}(\mathrm{mmol} / \mathrm{L})$, mean \pm SD $(n=972)^{\mathrm{a}}$ & $124.4 \pm 36.2$ & $108.7 \pm 17.1$ & $172.1 \pm 37.3$ & $<0.001$ & $1.29(1.23-1.36)$ & $<0.001$ \\
\hline Pre-pregnancy BMI $\left(\mathrm{kg} / \mathrm{m}^{2}\right)$, mean $\pm \mathrm{SD}$ & $21.2 \pm 3.3$ & $20.5 \pm 2.4$ & $23.5 \pm 4.4$ & $<0.001$ & $1.34(1.27-1.40)$ & $<0.001$ \\
\hline Birth weight $(g)$, mean $\pm S D$ & $3188.2 \pm 480.9$ & $3189.3 \pm 456.0$ & $3184.4 \pm 558.3$ & 0.97 & $1.00(0.99-1.00)$ & 0.89 \\
\hline SGA, n (\%) & $140(12.9)$ & 114 (13.6) & $26(10.5)$ & 0.21 & $0.75(0.48-1.18)$ & 0.21 \\
\hline AGA, n (\%) & $903(83.1)$ & $698(83.1)$ & $205(83.0)$ & 0.97 & $0.99(0.68-1.45)$ & 0.97 \\
\hline LGA, n (\%) & $44(4.1)$ & $28(3.3)$ & $16(6.5)$ & 0.028 & $2.01(1.07-3.78)$ & 0.030 \\
\hline Macrosomia, n (\%) & $43(4.1)$ & $29(3.5)$ & $14(5.7)$ & 0.12 & $1.68(0.87-3.23)$ & 0.12 \\
\hline Progesterone therapy & $1(0.1)$ & $0(0.0)$ & $1(0.4)$ & 0.23 & 3.40 (0.18-Infinity) & 0.46 \\
\hline Insulin therapy & $36(3.3)$ & $0(0.0)$ & $36(14.6)$ & $<0.001$ & 203.42 (45.29-Infinity) & $<0.001$ \\
\hline
\end{tabular}

SGA small for gestational age: $<10$ th percentile, $A G A$ appropriate for gestational age: 10th-90th percentile, LGA large for gestational age: $>90$ th percentile, Macrosomia Estimated fetal weight $\geq 4 \mathrm{~kg}[25]$

${ }^{\text {a } M i s s i n g ~ d a t a}$ are excluded from statistical analyses

${ }^{\mathrm{b}} \mathrm{Chi}$-square test or Fisher's exact test for categorical variables and Wilcoxon rank sum test for continuous variables

'Univariate logistic regression 
pregnancy when the pre-pregnancy weight was unknown) and measured height [14]. BMI was calculated as body mass in $\mathrm{kg}$ divided by height in $\mathrm{m}^{2}$. SGA $(<10$ th percentile), appropriate for gestational age (AGA) (10-90th percentile), large for gestational age (LGA) ( $>90$ th percentile), and macrosomia (estimated fetal weight $\geq 4000 \mathrm{~g}$ ) were defined for birth weight [30].

In this study, the association between threatened miscarriage and glucose intolerance was compared between the normal and GDM groups, between the normal and maternal hyperglycemia (borderline GDM and GDM groups) groups, and among the normal, borderline GDM, and GDM groups.

All analyses were performed using SAS software, version 9.2 (SAS Institute, Cary, NC, USA). To confirm that continuous variables were normally distributed, we applied the Shapiro-Wilk test. For non-normal distributed data, the significance of the differences between groups was tested using the Wilcoxon rank sum test. The categorical responses between the groups were analyzed using the chi-square test or Fisher's exact test. The associations of the independent risk factors with each group

Table 2 Clinical characteristics of the normal and maternal hyperglycemia (Borderline GDM and GDM groups) groups

\begin{tabular}{|c|c|c|c|c|c|c|}
\hline & $\begin{array}{l}\text { Total } \\
(n=1567)\end{array}$ & $\begin{array}{l}\text { Normal } \\
(n=840)\end{array}$ & $\begin{array}{l}\text { Borderline GDM and GDM } \\
(n=727)\end{array}$ & $p^{b}$ & OR $(95 \% \mathrm{Cl})$ & $p^{c}$ \\
\hline Maternal age (years), mean \pm SD & $33.8 \pm 3.9$ & $33.9 \pm 3.9$ & $33.7 \pm 4.0$ & 0.23 & $0.99(0.96-1.01)$ & 0.35 \\
\hline$<35, \mathrm{n}(\%)$ & $931(59.4)$ & $498(59.3)$ & $433(59.6)$ & 0.91 & ref & 0.91 \\
\hline$\geq 35, \mathrm{n}(\%)$ & $636(40.6)$ & $342(40.7)$ & $294(40.4)$ & & $0.99(0.81-1.21)$ & \\
\hline Parity, n (\%) & & & & 0.11 & & 0.11 \\
\hline Primipara & $892(56.9)$ & $494(58.8)$ & $398(54.7)$ & & ref & \\
\hline Multipara & $675(43.1)$ & $346(41.2)$ & $329(45.3)$ & & $1.18(0.97-1.44)$ & \\
\hline Intrauterine hematoma, n (\%) & $113(7.2)$ & $72(8.6)$ & $41(5.6)$ & 0.025 & $0.64(0.43-0.95)$ & 0.026 \\
\hline Gestational age at birth (weeks), mean \pm SD & $38.5 \pm 1.7$ & $38.8 \pm 1.4$ & $38.2 \pm 2.0$ & $<0.001$ & $0.81(0.76-0.86)$ & $<0.001$ \\
\hline Preterm delivery (before 37 weeks), n (\%) & $123(7.9)$ & $45(5.4)$ & $78(10.7)$ & $<0.001$ & $2.12(1.45-3.11)$ & $<0.001$ \\
\hline Delivery methods, n (\%) & & & & $<0.001$ & & \\
\hline Normal delivery & $1015(64.8)$ & $588(70.0)$ & $427(58.7)$ & & ref & \\
\hline Operative delivery (vacuum) & $22(1.4)$ & $10(1.2)$ & $12(1.7)$ & & $1.65(0.71-3.86)$ & 0.25 \\
\hline Primary cesarean section & $246(15.7)$ & $121(14.4)$ & $125(17.2)$ & & $1.42(1.08-1.88)$ & 0.013 \\
\hline Repeat cesarean section & $284(18.1)$ & $121(14.4)$ & $163(22.4)$ & & $1.86(1.42-2.42)$ & $<0.001$ \\
\hline PROM, n (\%) & $267(17.0)$ & $148(17.6)$ & $119(16.4)$ & 0.51 & $0.92(0.70-1.19)$ & 0.51 \\
\hline PPROM, n (\%) & $54(3.5)$ & $25(3.0)$ & $29(4.0)$ & 0.27 & $1.35(0.79-2.33)$ & 0.28 \\
\hline Preeclampsia, n (\%) & $35(2.2)$ & $8(1.0)$ & $27(3.7)$ & $<0.001$ & $4.01(1.81-8.89)$ & 0.001 \\
\hline Placenta previa, n (\%) & $35(2.2)$ & $17(2.0)$ & $18(2.5)$ & 0.56 & $1.23(0.63-2.41)$ & 0.55 \\
\hline Placenta abruption, n (\%) & $10(0.6)$ & $7(0.8)$ & $3(0.4)$ & 0.36 & $0.49(0.13-1.91)$ & 0.31 \\
\hline Still birth, n (\%) & $4(0.3)$ & $3(0.4)$ & $1(0.1)$ & 0.63 & $0.39(0.04-3.71)$ & 0.41 \\
\hline History of prior GDM, n (\%) & $58(3.7)$ & $1(0.1)$ & $57(7.8)$ & $<0.001$ & $71.20(9.86-514.24)$ & $<0.001$ \\
\hline $50 \mathrm{~g} \mathrm{OGCT}(\mathrm{mmol} / \mathrm{L})$, mean $\pm \mathrm{SD}(n=1445)^{\mathrm{a}}$ & $134.8 \pm 34.3$ & $108.7 \pm 17.1$ & $161.5 \pm 25.9$ & $<0.001$ & $1.42(1.34-1.50)$ & $<0.001$ \\
\hline Pre-pregnancy BMI $\left(\mathrm{kg} / \mathrm{m}^{2}\right)$, mean $\pm \mathrm{SD}$ & $21.2 \pm 3.3$ & $20.5 \pm 2.4$ & $22.1 \pm 4.0$ & $<0.001$ & $1.18(1.14-1.23)$ & $<0.001$ \\
\hline Birth weight $(\mathrm{g})$, mean $\pm \mathrm{SD}$ & $3186.7 \pm 485.0$ & $3189.3 \pm 456.0$ & $3183.6 \pm 516.7$ & 0.82 & $1.00(0.99-1.00)$ & 0.82 \\
\hline SGA, n (\%) & $187(11.9)$ & $114(13.6)$ & $73(10.0)$ & 0.032 & $0.71(0.52-0.97)$ & 0.032 \\
\hline AGA, n (\%) & 1319 (84.2) & $698(83.1)$ & $621(85.4)$ & 0.21 & $1.19(0.91-1.57)$ & 0.21 \\
\hline LGA, n (\%) & $61(3.9)$ & $28(3.3)$ & $33(4.5)$ & 0.22 & $1.38(0.83-2.31)$ & 0.22 \\
\hline Macrosomia, n (\%) & $59(3.8)$ & $29(3.5)$ & $30(4.1)$ & 0.48 & $1.20(0.72-2.03)$ & 0.48 \\
\hline Progesterone therapy & $3(0.2)$ & $0(0.0)$ & $3(0.4)$ & 0.10 & 4.46 (0.68-Infinity) & 0.20 \\
\hline Insulin therapy & $37(2.4)$ & $0(0.0)$ & $37(5.1)$ & $<0.001$ & 64.23 (14.36-Infinity) & $<0.001$ \\
\hline
\end{tabular}

SGA small for gestational age: $<10$ th percentile, AGA appropriate for gestational age: 10th-90th percentile, LGA large for gestational age: $>90$ th percentile, Macrosomia Estimated fetal weight $\geq 4 \mathrm{~kg}[25]$

${ }^{a}$ Missing data are excluded from statistical analyses

${ }^{\mathrm{b}} \mathrm{Chi}$-square test or Fisher's exact test for categorical variables and Wilcoxon rank sum test for continuous variables

'Univariate logistic regression 
Table 3 Association between GDM and threatened miscarriage

\begin{tabular}{|c|c|c|c|c|c|c|c|}
\hline & Total $(n=1087)$ & Normal $(n=840)$ & $\operatorname{GDM}(n=247)$ & OR $(95 \% \mathrm{Cl})$ & $p$ & Adjusted OR (95\% Cl) & $p$ \\
\hline Threatened miscarriage, n (\%) & & & & & 0.002 & & 0.009 \\
\hline Negative & $949(87.3)$ & $719(85.6)$ & $230(93.1)$ & ref & & ref & \\
\hline Positive & $138(12.7)$ & $121(14.4)$ & $17(6.9)$ & $0.44(0.26-0.75)$ & & $0.38(0.18-0.78)$ & \\
\hline $\begin{array}{l}\text { Amount of bleeding, } \mathrm{n}(\%) \\
(n=137)^{\mathrm{a}}\end{array}$ & & & & & 0.11 & & 0.69 \\
\hline Light & $117(85.4)$ & $100(83.3)$ & $17(100.0)$ & ref & & ref & \\
\hline Heavy & $20(14.6)$ & $20(16.7)$ & $0(0.0)$ & $0.21(0.00-1.05)$ & & $0.63(0.00-3.46)$ & \\
\hline $\begin{array}{l}\text { Number of bleeding episodes, } \mathrm{n}(\%) \\
(n=137)^{\mathrm{a}}\end{array}$ & & & & & 0.13 & & 0.53 \\
\hline$\leq 2$ & $108(78.8)$ & $92(76.7)$ & $16(94.1)$ & ref & & ref & \\
\hline$\geq 3$ & $29(21.2)$ & $28(23.3)$ & $1(5.9)$ & $0.21(0.03-1.62)$ & & $0.50(0.06-4.42)$ & \\
\hline
\end{tabular}

Statistical analyses were performed by univariable and multivariable logistic regression

The data were adjusted for maternal age ( $<35$ years, $\geq 35$ years), parity, history of prior GDM, pre-pregnancy BMl, progesterone therapy, and insulin therapy

${ }^{a}$ Missing data are excluded from statistical analyses

were analyzed using logistic regression, with or without adjusting for confounding factors. Confounding factors included maternal age ( $<35$ years, $\geq 35$ years), parity, history of prior GDM, gestational age at birth, and pre-pregnancy BMI, which are known risk factors for GDM [14, 31], and showed statistical significance in the current univariate analysis. According to a previous study, maternal age $>35$ years was a risk factor for GDM [31]. Data were also adjusted for progesterone and insulin therapy based on their influence on the study result. Hosmer-Lemeshow goodness-of-fit test was performed $(P>0.05)$ to identify the most appropriate model. $P<0.05$ was considered statistically significant.

\section{Results}

The clinical characteristics of the study population are presented in Tables 1 and 2. The GDM group showed a lower incidence of intrauterine hematoma and a lower gestational age at birth than the normal group. The absolute maternal age and the rates of women with a maternal age $\geq 35$ years, multiparity, preterm delivery, cesarean section, preeclampsia, history of prior GDM, pre-pregnancy BMI, and LGA were higher in the GDM group than in the normal group. The absolute birth weight and the incidence rates of operative delivery, premature rupture of membrane (PROM), PPROM, placenta previa, placenta abruption, stillbirth, SGA, and AGA, and macrosomia did not differ between the groups (Table 1 ). Additionally, the maternal hyperglycemia (borderline GDM and GDM groups) group exhibited a lower incidence of intrauterine hematoma and SGA, and a lower gestational age at birth than the normal group. The preterm delivery, cesarean section, preeclampsia, history of prior GDM, and pre-pregnancy BMI were higher in the maternal hyperglycemia (borderline GDM and GDM

Table 4 Association between maternal hyperglycemia (Borderline GDM and GDM) and threatened miscarriage

\begin{tabular}{|c|c|c|c|c|c|c|c|}
\hline & Total $(n=1567)$ & Normal $(n=840)$ & $\begin{array}{l}\text { Borderline GDM and } \\
\text { GDM }(n=727)\end{array}$ & OR $(95 \%$ Cl) & $p$ & $\begin{array}{l}\text { Adjusted OR } \\
(95 \% \mathrm{Cl})\end{array}$ & $p$ \\
\hline Threatened miscarriage, n (\%) & & & & & 0.009 & & 0.013 \\
\hline Negative & $1373(87.6)$ & 719 (85.6) & $654(90.0)$ & ref & & ref & \\
\hline Positive & $194(12.4)$ & $121(14.4)$ & $73(10.0)$ & $0.66(0.49-0.90)$ & & $0.66(0.47-0.91)$ & \\
\hline $\begin{array}{l}\text { Amount of bleeding, } \mathrm{n}(\%) \\
(n=192)^{\mathrm{a}}\end{array}$ & & & & & 0.29 & & 0.15 \\
\hline Light & $164(85.4)$ & $100(83.3)$ & $64(88.9)$ & ref & & ref & \\
\hline Heavy & $28(14.6)$ & $20(16.7)$ & $8(11.1)$ & $0.63(0.26-1.50)$ & & $0.66(0.26-1.67)$ & \\
\hline $\begin{array}{l}\text { Number of bleeding episodes, } n(\%) \\
(n=192)^{\text {a }}\end{array}$ & & & & & 0.022 & & 0.14 \\
\hline$\leq 2$ & $157(81.8)$ & $92(76.7)$ & $65(90.3)$ & ref & & ref & \\
\hline$\geq 3$ & 35 (18.2) & $28(23.3)$ & $7(9.7)$ & $0.35(0.15-0.86)$ & & $0.36(0.14-0.93)$ & \\
\hline
\end{tabular}

Statistical analyses were performed by univariable and multivariable logistic regression

The data were adjusted for maternal age ( $<35$ years, $\geq 35$ years), parity, history of prior GDM, pre-pregnancy BMI, progesterone therapy, and insulin therapy ${ }^{a}$ Missing data are excluded from statistical analyses 
Table 5 Association between the severity of maternal hyperglycemia and threatened miscarriage: Multinomial logistic regression

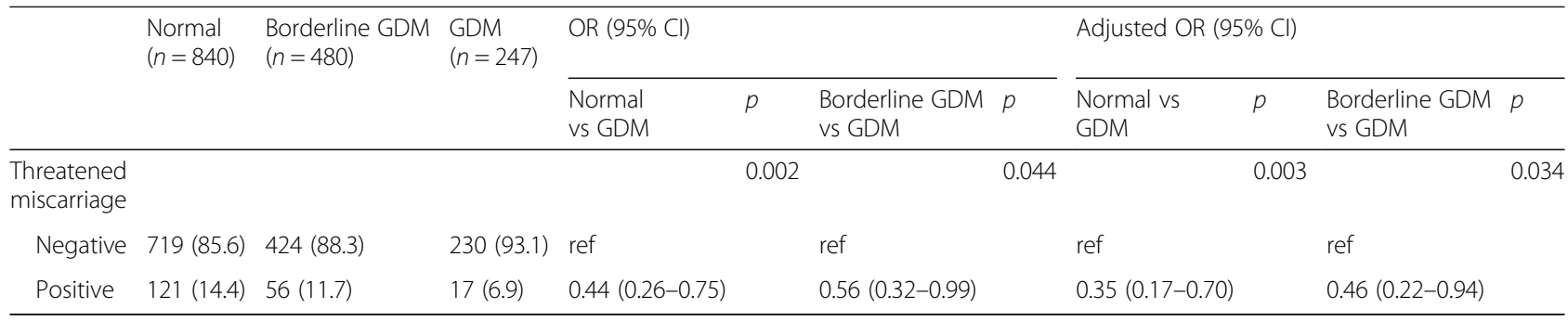

Statistical analyses were performed by univariable and multivariable logistic regression

The data were adjusted for maternal age ( $<35$ years, $\geq 35$ years), parity, history of prior GDM, pre-pregnancy BMl, progesterone therapy, and insulin therapy

groups) group than in the normal group. Other variables were not different between the groups (Table 2).

The proportion of women who experienced threatened miscarriage was significantly lower in the GDM group than in the normal group with or without adjusting for confounding factors (adjusted odds ratio (OR), 0.38; 95\% confidence interval (CI), 0.18-0.78; $P=0.009$ ) (Table 3). It was also significantly lower in the maternal hyperglycemia (borderline GDM and GDM groups) group than in the normal group (adjusted OR, 0.66; 95\% CI, 0.47-0.91; $P=0.013$ ) (Table 4). The amount of bleeding and the number of bleeding episodes in women who experienced threatened miscarriage were not different between the groups (Tables 3 and 4).

Threatened miscarriage showed significant associations among the normal, borderline GDM, and GDM groups. The proportion of women who experienced threatened miscarriage was significantly lower in the GDM group than in the normal group with or without adjusting for confounding factors (adjusted OR, 0.35; 95\% CI, $0.17-0.70 ; P=0.003)$. The proportion of women who experienced threatened miscarriage was also significantly lower in the GDM group than in the borderline GDM group with or without adjusting for confounding factors (adjusted OR, 0.46; 95\% CI, 0.22-0.94; $P=0.034$ ). Moreover, the proportion of women who experienced threatened miscarriage significantly decreased according to the severity of glucose intolerance with or without adjusting for confounding factors (adjusted OR, 0.94; 95\% CI, $0.76-1.16 ; P<0.001$ ) (Tables 5 and 6 ).

\section{Discussion}

In this case-control study, we found that the women who experienced threatened miscarriage had a significantly decreased risk of GDM in current pregnancies. This finding was observed in the comparison between the normal and GDM groups, between the normal and maternal hyperglycemia (borderline GDM and GDM groups) groups, and among the normal, borderline GDM, and GDM groups. Moreover, threatened miscarriage showed an inverse correlation with the severity of glucose intolerance. Our data supported our initial hypothesis that low progesterone levels in women with threatened miscarriage might be associated with a low increase in insulin resistance during the second and third trimesters of pregnancy, followed by a low incidence of glucose intolerance. Our findings potentially aids in understanding these common complications of pregnancy. However, future prospective, large-scale studies are necessary to explore the relationship between threatened miscarriage and GDM.

A prospective pilot study based on a small population with a very low incidence of GDM [threatened miscarriage vs normal pregnancy, $3 / 69(4.3 \%)$ vs $11 / 564$ (2.0\%), respectively] reported no relationship between threatened miscarriage and GDM [27]. By contrast, our study (normal pregnancy vs GDM with or without borderline GDM) retrospectively showed relatively lower incidences of GDM and maternal hyperglycemia (borderline GDM and GDM) in women who experienced threatened miscarriage [27]. However, in a large-scale retrospective study involving women who received intramuscular high-dosage progesterone therapy (the total accumulated dose was $\geq 500 \mathrm{mg}$ ) due to threatened miscarriage in the second and third months of pregnancy, the incidence of GDM was slightly higher in women with threatened miscarriage [37/532 (6.95\%)] than in women with normal pregnancy [1141/21,054 (5.42\%)], but it was not statistically significant [20]. In the same study, threatened miscarriage was

Table 6 Association between the severity of maternal hyperglycemia and threatened miscarriage: Ordinal logistic regression

\begin{tabular}{|c|c|c|c|c|c|c|c|}
\hline & Normal $(n=840)$ & Borderline GDM $(n=480)$ & GDM $(n=247)$ & OR $(95 \% \mathrm{Cl})$ & $p$ & Adjusted OR (95\% Cl) & $p$ \\
\hline Threatened miscarriage & & & & & 0.003 & & $<0.001$ \\
\hline Negative & 719 (85.6) & $424(88.3)$ & $230(93.1)$ & ref & & ref & \\
\hline Positive & $121(14.4)$ & $56(11.7)$ & $17(6.9)$ & $0.63(0.47-0.86)$ & & $0.94(0.76-1.16)$ & \\
\hline
\end{tabular}

Statistical analyses were performed by univariable and multivariable logistic regression

The data were adjusted for maternal age ( $<35$ years, $\geq 35$ years), parity, history of prior GDM, pre-pregnancy BMI, progesterone therapy, and insulin therapy 
not associated with an increased risk of adverse obstetric and perinatal outcomes, such as preterm delivery, hypertensive disorders in pregnancy, placenta previa, placenta abruption, live births, and low birth weight, compared with normal pregnancy [20]. These findings demonstrate that the risks of common adverse obstetric and perinatal outcomes of threatened miscarriage were affected by progesterone therapy. In particular, considering the effect of progesterone therapy, we speculate that threatened miscarriage in the previous study might be associated with a low risk of GDM, which corresponded with the results of our study that showed inverse correlation between threatened miscarriage and GDM (Tables 3, 5 and 6).

Intrauterine hematoma is detected in $18-39 \%$ of pregnant women who experience threatened miscarriage. It is associated with an increased risk of adverse obstetric outcomes, such as preterm delivery, pregnancy-induced hypertension, preeclampsia, placental abruption, and SGA, through mechanisms that are similar to those that result in threatened miscarriage $[1,3]$. In the present study, the incidence of intrauterine hematoma (50.5\%) in women with threatened miscarriage was higher than that described in previous reports [3]. Moreover, the incidence of intrauterine hematoma decreased in women with GDM and maternal hyperglycemia (borderline GDM and GDM) compared with the normal women, in accordance with the risk of threatened miscarriage (Tables 1 and 2).

The amount of vaginal bleeding during pregnancy is a subjective measurement. Consequently, distinguishing between light and heavy vaginal bleeding has not been effective [6]. In our study, although the data did not reach statistical significance, GDM and maternal hyperglycemia (borderline GDM and GDM) occurred less frequently in women with heavy bleeding than in women with light bleeding. They also occurred less frequently in women with higher bleeding levels $(\geq 3)$ than in women with lower bleeding levels $(\leq 2)$, which is in accordance with the risk of threatened miscarriage (Tables 3 and 4).

In our study, the GDM group displayed typical characteristics of women with GDM compared with the normal group, which is in accordance with prior reports (Table 1) [30-33]. However, compared with previous reports [34-36], we detected a similar birth weight, low pre-pregnancy BMI and rates of macrosomia/LGA, and a high rate of SGA in the study cohort. This result suggests inherent ethnic differences in which Koreans consider lean body shape as superior to obese, followed by excessive diet control and exercise (Table 1). Additionally, in contrast to prior studies that reported higher birth weight, higher macrosomia/LGA rates, and lower SGA rates in women with GDM [35-37], the birth weight and the incidence rate of SGA, LGA, or macrosomia were unchanged in women with GDM and maternal hyperglycemia (borderline GDM and GDM) compared with the normal women in our study
(Tables 1 and 2). These findings could be explained by the low pre-pregnancy BMI and the low rates of macrosomia/ LGA in our study groups in addition to the higher preterm delivery rate and the shorter gestational age at birth in women with GDM and maternal hyperglycemia (borderline GDM and GDM) compared with the normal women.

The significance of our study might be limited because definite mechanisms to elucidate the relationship between threatened miscarriage, and GDM and the severity of glucose intolerance were not clinically investigated. However, our study is important because it focused on their specific relationship, although it was performed using a retrospective design.

\section{Conclusions}

In this retrospective study, we demonstrated that GDM was less frequently observed in Korean women who experienced threatened miscarriage showing inverse relationship between threatened miscarriage and the severity of glucose intolerance. Further research is recommended to confirm these relationships and to evaluate the pathophysiologic mechanisms that interplay between these common obstetric complications. We believe that these interesting findings will help improved care for women with adverse obstetric outcomes.

\section{Abbreviations \\ AGA: Appropriate for gestational age; BMI: Body mass index; CRL: Crown- rump length; GDM: Gestational diabetes mellitus; LGA: Large for gestational age; LMP: Last menstrual period; OGCT: Oral glucose challenge test; OGTT: Oral glucose tolerance test; PPROM: Preterm premature rupture of membrane; SGA: Small for gestational age}

\section{Acknowledgments}

Statistical support was provided by the Catholic Research Coordinating Center of the Korea Health 21 Research \& Development Project (No. A070001), Ministry of Health and Welfare, Republic of Korea.

\section{Availability of data and materials}

The dataset analyzed during the current study is included within the article. More information will be available from the corresponding author on reasonable request.

\section{Authors' contributions}

$H J L, E N$, and $B L$ participated in designing the research. $H J L$ and $B L$ participated in field data collection and conducted statistical analyses. BL wrote the manuscript, and $\mathrm{HJ}$ and EN read and commented on it. The final paper submitted for publication was read and approved by HJL, EN, and BL.

\section{Ethics approval and consent to participate}

This study was approved by the Institutional Review Board of The Catholic Medical Center at the Catholic University of Korea (No. XC14RIMI0013U) on February 1, 2014. We were permitted to access patient medical records in Seoul or Uijeongbu St. Mary's Hospital at the Catholic University of Korea involved in our study. Informed consent was waived based on IRB guidelines.

Consent for publication

Not applicable.

Competing interests

The authors declare that they have no competing interests. 


\section{Publisher's Note}

Springer Nature remains neutral with regard to jurisdictional claims in published maps and institutional affiliations.

\section{Author details}

${ }^{1}$ Department of Obstetrics \& Gynecology, College of Medicine, The Catholic University of Korea, Seoul, Republic of Korea. ${ }^{2}$ Department of Obstetrics \& Gynecology, Tufts University School of Medicine, Boston, MA, USA. ${ }^{3}$ Department of Obstetrics and Gynecology, Hallym University Kangdong Sacred Heart Hospital, 150, Seongan-ro, Gangdong-gu, Seoul, Republic of Korea

Received: 20 December 2017 Accepted: 27 July 2018

Published online: 06 August 2018

\section{References}

1. Jauniaux E, Van Oppenraaij RH, Burton GJ. Obstetric outcome after early placental complications. Curr Opin Obstet Gynecol. 2010;22:452-7.

2. Park C, Kang MY, Kim D, Park J, Eom H, Kim EA. Prevalence of abortion and adverse pregnancy outcomes among working women in Korea: a crosssectional study. PLoS One. 2017;12(8):e0182341.

3. van Oppenraaij RH, Jauniaux E, Christiansen OB, Horcajadas JA, Farquharson $R G$, Exalto N. Predicting adverse obstetric outcome after early pregnancy events and complications: a review. Hum Reprod Update. 2009;15:409-21.

4. Dadkhah F, Kashanian M, Eliasi G. A comparison between the pregnancy outcome in women both with or without threatened abortion. Early Hum Dev. 2010;86:193-6.

5. Weiss JL, Malone FD, Vidaver J, Ball RH, Nyberg DA, Comstock CH, et al. Threatened abortion: a risk factor for poor pregnancy outcome, a population-based screening study. Am J Obstet Gynecol. 2004;190:745-50

6. Saraswat L, Bhattacharya S, Maheshwari A, Bhattacharya S. Maternal and perinatal outcome in women with threatened miscarriage in the first trimester: a systematic review. BJOG. 2010;117:245-57.

7. Buchanan TA, Xiang AH, Page KA. Gestational diabetes mellitus: risks and management during and after pregnancy. Nat Rev Endocrinol. 2012:8:639-49.

8. American Diabetes Association. Gestational diabetes mellitus. Diabetes Care. 2003;26(suppl 1)::103-5.

9. No PB. 137: gestational diabetes mellitus. Obstet Gynecol. 2013;122(2 Pt 1):406-16.

10. Han $\mathrm{S}$, Crowther CA, Middleton P. Interventions for pregnant women with hyperglycaemia not meeting gestational diabetes and type 2 diabetes diagnostic criteria. Cochrane Database Syst Rev. 2012;1:CD009037.

11. Mulla WR, Henry TQ, Homko CJ. Gestational diabetes screening after HAPO: has anything changed? Curr Diab Rep. 2010;10:224-8.

12. Koo BK, Lee JH, Kim J, Jang EJ, Lee CH. Prevalence of gestational diabetes mellitus in Korea: a National Health Insurance Database Study. PLoS One. 2016;11(4):e0153107.

13. Han S, Middleton PF, Bubner TK, Crowther CA. Women's views on their diagnosis and management for borderline gestational diabetes mellitus. J Diabetes Res. 2015:2015:209215

14. Park TC, Lee BH, Norwitz ER, Lee HJ. Maternal hyperglycemia and the 100-g oral glucose tolerance test. Taiwan J Obstet Gynecol. 2015;54(2):137-42.

15. Nakajima ST, Nason FG, Badger GJ, Gibson M. Progesterone production in early pregnancy. Fertil Steril. 1991;55:516-21.

16. Mesiano S, Wang Y, Norwitz ER. Progesterone receptors in the human pregnancy uterus: do they hold the key to birth timing? Reprod Sci. 2011; 18:6-19.

17. Qureshi NS. Treatment options for threatened miscarriage. Maturitas. 2009, 65(Suppl 1):S35-41.

18. Carp H. A systematic review of dydrogesterone for the treatment of recurrent miscarriage. Gynecol Endocrinol. 2015;31:422-30.

19. Wahabi HA, Fayed AA, Esmaeil SA, Al Zeidan RA. Progestogen for treating threatened miscarriage. Cochrane Database Syst Rev. 2011;(12):CD005943. https://doi.org/10.1002/14651858.CD005943.pub4. Review.

20. Duan L, Yan D, Zeng W, Yang X, Wei Q. Effect of progesterone treatment due to threatened abortion in early pregnancy for obstetric and perinatal outcomes. Early Hum Dev. 2010;86:41-3.

21. Carr DB, Gabbe S. Gestational diabetes: detection, management, and implications. Clin Diabetes. 1998;16:4-11.

22. Ryan $E A$, Enns $L$. Role of gestational hormones in the induction of insulin resistance. J Clin Endocrinol Metab. 1988;67:341-7.
23. Wada T, Hori S, Sugiyama M, Fujisawa E, Nakano T, Tsuneki H, et al. Progesterone inhibits glucose uptake by affecting diverse steps of insulin signaling in 3T3-L1 adipocytes. Am J Physiol Endocrinol Metab. 2010:298:E881-8.

24. Picard F, Wanatabe M, Schoonjans K, Lydon J, O'Malley BW, Auwerx J. Progesterone receptor knockout mice have an improved glucose homeostasis secondary to beta -cell proliferation. Proc Natl Acad Sci U S A. 2002;99:15644-8.

25. Egerman R, Ramsey R, Istwan N, Rhea D, Stanziano G. Maternal characteristics influencing the development of gestational diabetes in obese women receiving 17-alpha-hydroxyprogesterone caproate. J Obes. 2014;2014:563243

26. Rebarber A, Istwan NB, Russo-Stieglitz K, Cleary-Goldman J, Rhea DJ, Stanziano GJ, et al. Increased incidence of gestational diabetes in women receiving prophylactic 17alpha-hydroxyprogesterone caproate for prevention of recurrent preterm delivery. Diabetes Care. 2007;30:2277-80.

27. Calleja-Agius J, Calleja N, Brincat M, Spiteri D. Obstetric outcome in cases of threatened spontaneous abortion. Int J Gynaecol Obstet. 2010;110:75-6.

28. Carpenter MW, Coustan DR. Criteria for screening tests for gestational diabetes. Am J Obstet Gynecol. 1982;144:768-73.

29. Scorza WE, Vintzileos A. First and second trimester sonography: an American perspective. Int J Fertil Menopausal Stud. 1996:41(3):288-92.

30. Metzger BE, Lowe LP, Dyer AR, Trimble ER, Chaovarindr U, Coustan DR, et al. Hyperglycemia and adverse pregnancy outcomes. N Engl J Med. 2008;358:1991-2002.

31. Galtier F. Definition, epidemiology, risk factors. Diabetes Metab. 2010;36:628-51.

32. Beucher G, Viaris de Lesegno B, Dreyfus M. Maternal outcome of gestational diabetes mellitus. Diabetes Metab. 2010;36(6 Pt 2):522-37.

33. Riskin-Mashiah S, Damti A, Younes G, Auslander R. Pregestational body mass index, weight gain during pregnancy and maternal hyperglycemia. Gynecol Endocrinol. 2011:27:464-7.

34. Most O, Langer O. Gestational diabetes: maternal weight gain in relation to fetal growth, treatment modality, BMl and glycemic control. J Matern Fetal Neonatal Med. 2012;25:2458-63.

35. Hillier TA, Pedula KL, Vesco KK, Schmidt MM, Mullen JA, LeBlanc ES, et al. Excess gestational weight gain: modifying fetal macrosomia risk associated with maternal glucose. Obstet Gynecol. 2008:112:1007-14.

36. Ellerbe CN, Gebregziabher M, Korte JE, Mauldin J, Hunt KJ. Quantifying the impact of gestational diabetes mellitus, maternal weight and race on birthweight via quantile regression. PLoS One. 2013;8:e65017.

37. Gonzalez Gonzalez NL, Goya M, Bellart J, Lopez J, Sancho MA, Mozas J, et al. Obstetric and perinatal outcome in women with twin pregnancy and gestational diabetes. J Matern Fetal Neonatal Med. 2012;25:1084-9.

Ready to submit your research? Choose BMC and benefit from:

- fast, convenient online submission

- thorough peer review by experienced researchers in your field

- rapid publication on acceptance

- support for research data, including large and complex data types

- gold Open Access which fosters wider collaboration and increased citations

- maximum visibility for your research: over $100 \mathrm{M}$ website views per year

At BMC, research is always in progress.

Learn more biomedcentral.com/submissions 